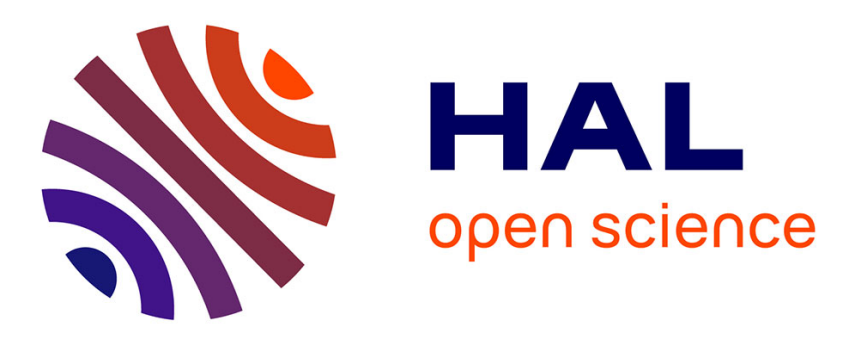

\title{
Simulation of the extrusion of hollow profiles by natural element methods
}

Iciar Alfaro, Francesco Gagliardi, Jose Olivera, Elías Cueto, Luigino Filice, Francisco Chinesta

\section{- To cite this version:}

Iciar Alfaro, Francesco Gagliardi, Jose Olivera, Elías Cueto, Luigino Filice, et al.. Simulation of the extrusion of hollow profiles by natural element methods. International Journal of Material Forming, 2009, 2 (Suppl 1), pp.597-600. 10.1007/s12289-009-0614-6 . hal-01513344

\author{
HAL Id: hal-01513344 \\ https://hal.science/hal-01513344
}

Submitted on 25 Apr 2017

HAL is a multi-disciplinary open access archive for the deposit and dissemination of scientific research documents, whether they are published or not. The documents may come from teaching and research institutions in France or abroad, or from public or private research centers.
L'archive ouverte pluridisciplinaire HAL, est destinée au dépôt et à la diffusion de documents scientifiques de niveau recherche, publiés ou non, émanant des établissements d'enseignement et de recherche français ou étrangers, des laboratoires publics ou privés. 


\title{
SIMULATION OF THE EXTRUSION OF HOLLOW PROFILES BY NATURAL ELEMENT METHODS
}

\author{
I. Alfaro ${ }^{1 *}$, F. Gagliardi ${ }^{2}$, J. Olivera ${ }^{1}$, E. Cueto ${ }^{1}$, L. Filice ${ }^{2}$, F. Chinesta ${ }^{3}$ \\ ${ }^{1}$ I3A, University of Zaragoza, Spain. \\ ${ }^{2}$ Dept. of Mechanical Engineering, University of Calabria, Italy. \\ ${ }^{3}$ EADS Corporate International Chair. Ecole Centrale de Nantes, France.
}

\begin{abstract}
In this paper, the Natural Element Method (NEM) together with the alpha shapes and some extra numerical procedures are used in the simulation of hollow profiles, emphasizing on the simulation of the welding lines. Numerical results are compared with experimental ones, checking the accuracy of the method.
\end{abstract}

KEYWORDS: Extrusion, welding line, hollow profile, meshless methods, NEM

\section{INTRODUCTION}

Extrusion is one of the most utilized processes among the bulk metal forming ones. The introduction of the Finite Element modeling and, in particular, the development of high efficient mesh management procedures, allowed the simulation of very complex processes characterized by large surfaces generation, high strains and strain rate.

Extrusion of hollow profiles is a key process as far as lightweight and efficient structures are regarded, without using secondary processes such as bending and welding. Optimization of such processes today is mainly carried out by experiments, using trial and error techniques, mainly due to the unsuitability of the FEM based commercial codes. On the numerical simulation of the hollow components extrusion it is very important to model properly the material joining in the welding chamber after the bridge. As can be seen on figures 1 and 2, slightly differences on the die geometry and extrusion conditions lead to success or fail on the extrusion of a tube.

The Natural Element Method (NEM) presents some advantages over Finite Element simulations, such as no remeshing requirements or the accuracy of the approximation even with highly irregular clouds of nodes. The meshless characteristic of NEM is also very adequate to simulate the creation and joining of free surfaces, as occurs during extrusion of hollow profiles. It is also possible to detect and simulate the welding lines formed when the material is joined after the porthole, checking if the resulting profile welds as it was predicted.

\section{$2 \alpha$-NEM}

\subsection{NEM}

Essentially, the NEM is a Galerkin procedure that relies on natural neighbor interpolation to construct the trial

\footnotetext{
*Corresponding author: iciar@unizar.es +34976761912
}

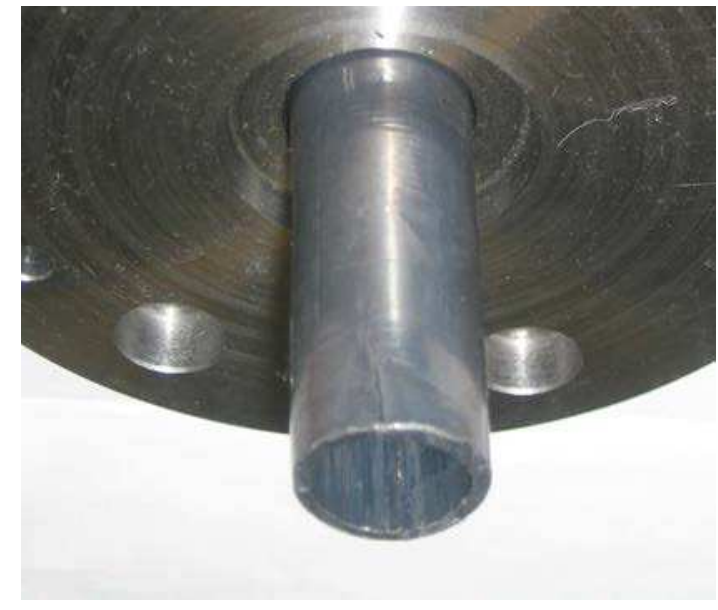

Figure 1: Extrusion of a tube

and test functions characteristic of this method. Consider a model composed by a cloud of points $\mathbf{N}=$ $\left\{n_{1}, n_{2}, \ldots, n_{m}\right\} \subset \mathbb{R}^{d}$, for which there is a unique decomposition of the space into regions such that each point within these regions is closer to the node to which the region is associated than to any other in the cloud. This kind of space decomposition is called a Voronoi diagram of the cloud of points and each Voronoi cell is formally defined as:

$$
T_{I}=\left\{\boldsymbol{x} \in \mathbb{R}^{d}: d\left(\boldsymbol{x}, \boldsymbol{x}_{I}\right)<d\left(\boldsymbol{x}, \boldsymbol{x}_{J}\right) \forall J \neq I\right\},
$$

where $d(\cdot, \cdot)$ is the Euclidean distance function. Two nodes sharing a facet of their Voronoi cell are called natural neighbours and hence the name of the technique. The dual structure of the Voronoi diagram is the Delaunay triangulation. Natural neighbours of a given node are those nodes that share with it an edge of a Delaunay triangle or tetrahedron 1 In the NEM framework, different interpolants have been 


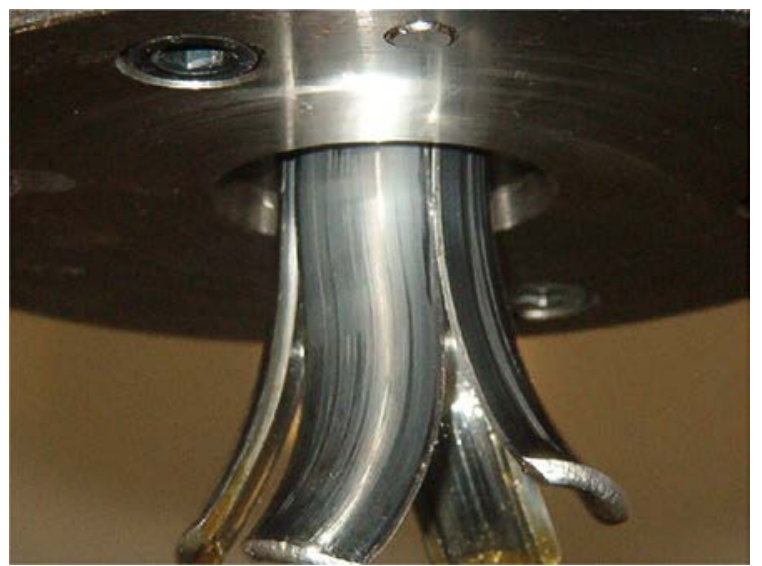

Figure 2: Faulty tube extrusion

proposed. The original version of the method [1] employed natural neighbour (Sibson) interpolation [2]. Sibson interpolation is very well-known in the approximation community as a high-quality interpolation scheme with many advantages (see, for instance, [3]). Sukumar [4] later proposed the use of Laplace (also known as nonSibsonian) interpolation [5]. This interpolant, used in this paper, is considerably less costly than the original Sibson interpolant, although somewhat less smooth.

If we define the distance $h_{J}=d\left(\boldsymbol{x}, \boldsymbol{x}_{J}\right)$ and the cell intersection $\boldsymbol{m}_{I J}=\left\{\boldsymbol{x} \in T_{I} \bigcap T_{J}, J \neq I\right\}$ (see Fig. 3 for an example), we can define the value

$$
\alpha_{J}(\boldsymbol{x})=\frac{\left|\boldsymbol{m}_{\boldsymbol{x} J}\right|}{h_{J}} .
$$

The shape function related to node I at point $\boldsymbol{x}$ is then defined as

$$
\phi_{I}^{n s}(\boldsymbol{x})=\frac{\alpha_{I}(\boldsymbol{x})}{\sum_{J=1}^{n} \alpha_{J}(\boldsymbol{x})} .
$$

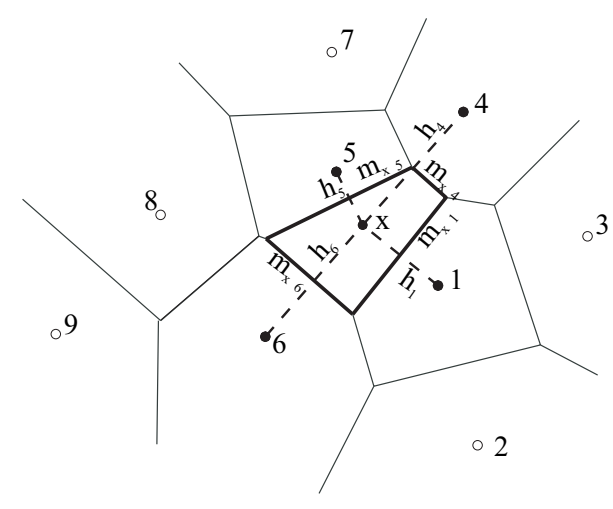

Figure 3: Definition of non-Sibsonian coordinates.

\section{2 $\alpha$ SHAPES}

When dealing with processes involving free surface flows, such as extrusion of hollow profiles, it is very important to accurately track their positions. Since meshless methods only use clouds of nodes, it is necessary to use shape con- structors, which are geometrical entities that give a continuous shape to a discrete cloud of nodes. One of such constructors is the family of $\alpha$-shapes of the cloud [6].

A cloud of points defines a finite set of shapes that can be parameterized by the level of detail up to which we want to represent the geometry. The idea behind $\alpha$-shapes is simple: those triangles (or tetrahedra in 3D) of the Delaunay triangulation whose circumradius is greater than the desired level of detail, say $\alpha$, are eliminated from the shape constructor. Figure 4 show an example of the different $\alpha$-shapes for a cloud of five nodes and different $\alpha$ values.

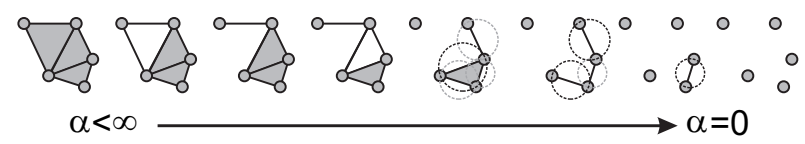

Figure 4: $\alpha$-shapes.

Constructing the model by taking into account the actual shape of the domain has consequences not only in geometrical aspects of the method, but also in the quality of the approximation. As demonstrated in [7], the use of a proper $\alpha$-shape for the definition of the domain ensures the linear interpolation of the essential field along the boundary.

\section{WELDING FLOWS SIMULATION}

As stated before, small differences on the die geometry can produce important defects on the extruded profile.An evidence of its importance can be found in several works present in literature which deal about its shape optimization.

Compromises among different needs have to be considered; Valberg [8], for example, stated that the size of the welding chamber has to be designed as a trade-off between an optimum die strength and pressure conditions. In fact, for the first greatness, the chamber should be narrow while, on the other hand, the ideal pressure and, consequently, a complete die filling are achieved with wider dimensions. The height of the welding chamber is another parameter that has to be carefully analyzed to improve the quality of the final extruded component. Donati et al. [9], tested different chamber heights obtaining the best weld qualities for the largest value. Moreover, it has to be said that welding pressure is influenced by many other process variables, such as the extrusion ratio, the punch speed, billet and die temperature [10].

The defect studied in this paper is the lack of welding of the extruded flows due to an insufficient pressure on the welding chamber.

The method proposed here modifies the creation algorithm of the $\alpha$-shape to include the effect of the pressure on it. During the simulation pressure of the nodes is tracked and saved. Every time a new $\alpha$-shape has to be done, pressure of the nodes of every triangle whose nodes belongs to two different flows is checked. If nodes 2 of this triangle have ever had a pressure higher than a cer- 
tain value, called required welding pressure, then this triangle is considered as definitely welded. Otherwise, the weld is not fully created. When a triangle with a good welding has a negative pressure, meaning that the weld tries to open, the triangle is kept in the $\alpha$-shape. When the welding tries to open through a not well welded triangle, this triangle is deleted and the crack is open.

The following figures show two test examples. On the first case a very low required welding pressure is defined, thus the weld is created. Figure 5 presents in blue color the welded area. On the second case a very high required welding pressure is defined, so the welding is not created and the tube is not correctly extruded (see Figure 6).

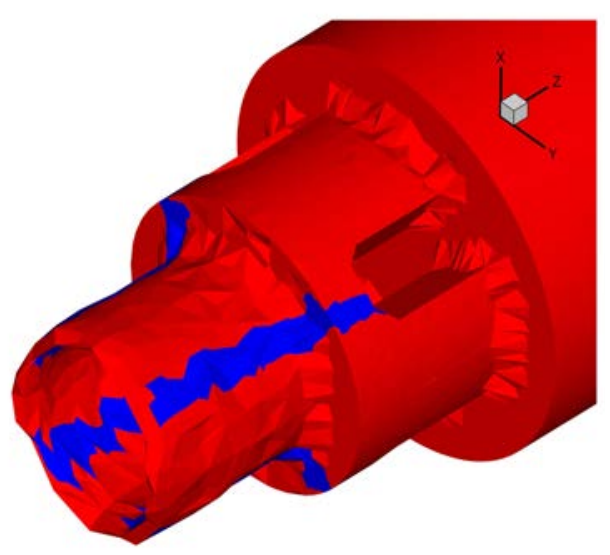

Figure 5: Welding is created. Welded area.

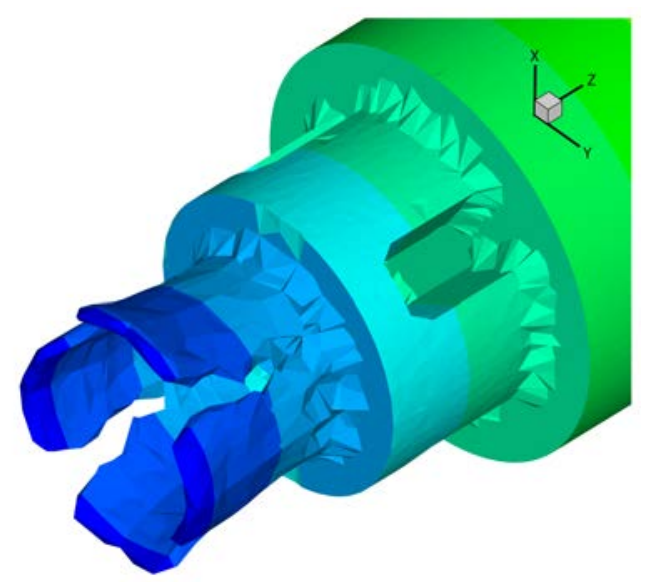

Figure 6: Welding is not created.

\section{SIMULATION OF TUBE EXTRUSION}

In order to check the accuracy and robustness of the method, a simulation of a real extrusion tube of $11 \mathrm{~mm}$ external diameter and $2 \mathrm{~mm}$ thickness has been done, and the results are compared with the experimental ones. The tube is made of lead, since this material behaves as viscoplastic at low temperature, so extrusion can be done at room temperature. Before performing the extrusion experiment, a complete series of material tests have been done in order to characterize its properties. On the simulation, the viscoplastic behavior has been modeled with the equation $\boldsymbol{\sigma}=60 \boldsymbol{d}^{0.1}$, where $\boldsymbol{d}$ is the equivalent strain rate defined as $\boldsymbol{d}=\sqrt{\frac{2}{3} \varepsilon: \varepsilon}$.

In a previous paper [11], the pressure inside the extrusion zone was measured experimentally using a proper equipment. Then, this measure was used to calibrate a commercial FE code in order to rebuild the pressure distribution all over the extruded material. In this way, it was shown that the required welding pressure threshold is about 150 MPa for the investigated case.

On the welding simulation, the modified $\alpha$-NEM code has been used, imposing the welding pressure of 150MPa. Due to symmetry, only one quarter of the profile has been simulated using a cloud of 2580 nodes to create the initial $\alpha$-shape.

Figure 7 shows the pressure value on the welding chamber area. It can be seen that only one region, far from the exit area, has a pressure higher than $150 \mathrm{MPa}$. Since material in this area doesn't flow through the exit, this weld is not propagated and the welding won't take place. Figure 8 shows how the weld is not created and a crack appears. Results are in agreement with experimental ones, shown in figure 9 .

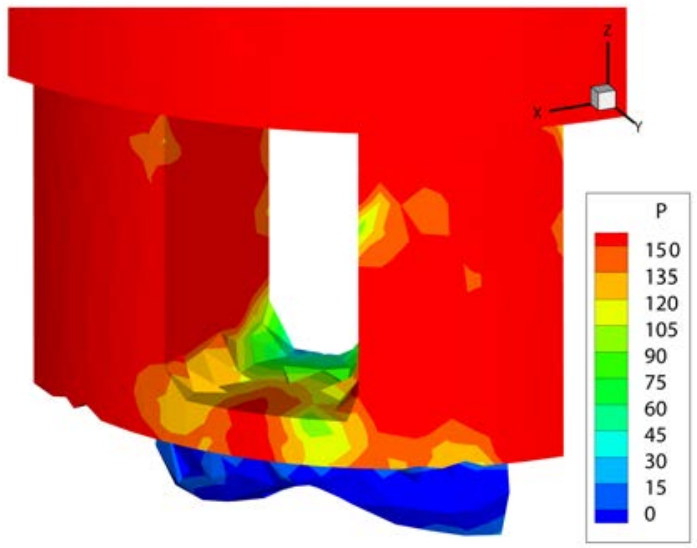

Figure 7: Simulated pressure.

\section{CONCLUSIONS}

Up to now the FE codes have been used to simulate the process but the unavailability to model the welding line evolution is one of the main drawbacks of this approach.

Although the Natural Element Method together with the $\alpha$-shapes has been already used to simulate extrusion processes and many other processes with free surfaces, it is 3 the first time it is used to study the welding lines formed in 


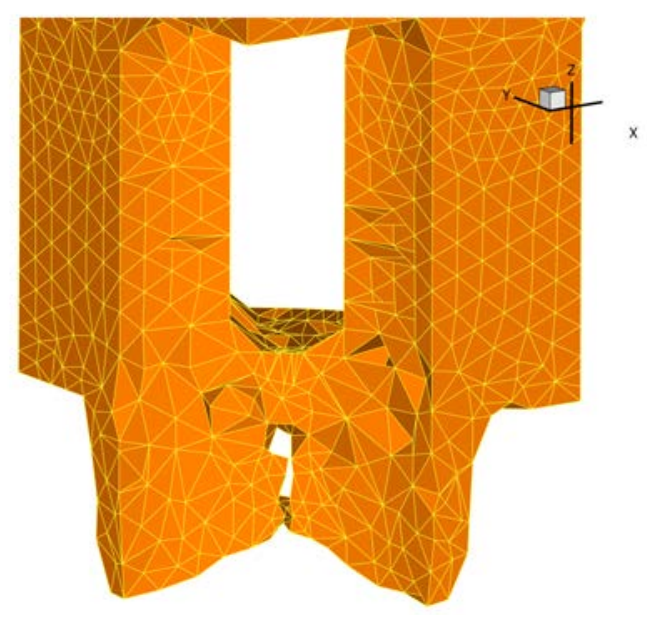

Figure 8: Simulated $\alpha$-shape.

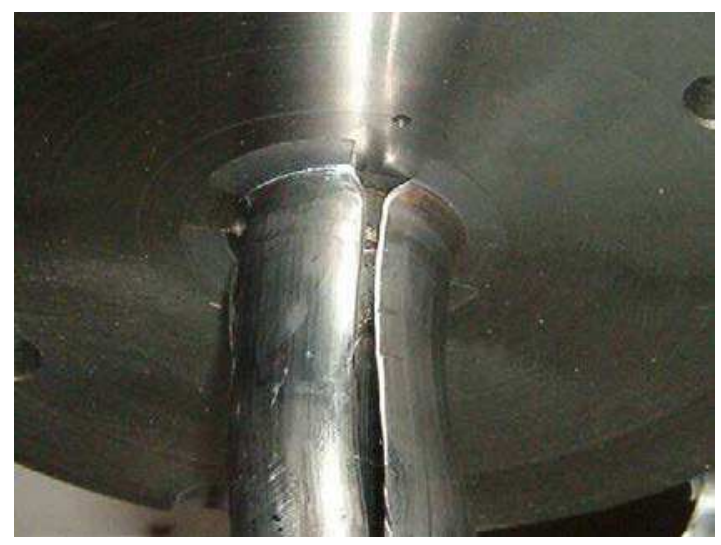

Figure 9: Experimental results.

the extrusion of hollow profiles. Taking into account the history of the nodes and thanks to the meshless characteristic of the method, it is possible to modify the $\alpha$-shapes to detect when the welding line is well created.

Both the academical example and the simulation corresponding to the real experimental test, confirm that the objective of simulating the behavior of the welding line is fulfilled.

\section{REFERENCES}

[1] J. Braun and M. Sambridge. A numerical method for solving partial differential equations on highly irregular evolving grids. Nature, 376:655-660, 1995.

[2] R. Sibson. A Vector Identity for the Dirichlet Tesselation. Mathematical Proceedings of the Cambridge Philosophical Society, 87:151-155, 1980.

[3] H. Hiyoshi. A numerical comparison of the natural neighbor interpolation and the finite element method. In K. Sugihara, editor, International Symposium on Voronoi diagrams in Science and Engineering, pages 1-10. University of Tokio,
2004.

[4] N. Sukumar, B. Moran, A. Yu Semenov, and V. V. Belikov. Natural Neighbor Galerkin Methods. International Journal for Numerical Methods in Engineering, 50(1):1-27, 2001.

[5] H. Hiyoshi and K. Sugihara. Two generalizations of an interpolant based on Voronoi diagrams.

International Journal of Shape Modeling, 5(2): 219-231, 1999.

[6] H. Edelsbrunner and E. Mücke. Three dimensional alpha shapes. ACM Transactions on Graphics, 13: 43-72, 1994.

[7] E. Cueto, M. Doblaré, and L. Gracia. Imposing essential boundary conditions in the Natural Element Method by means of density-scaled $\alpha$-shapes. International Journal for Numerical Methods in Engineering, 49-4:519-546, 2000.

[8] H. Valberg. Extrusion welding in aluminium extrusion. International Journal of Materials and Product Technology, 17, 7:497-556, 2003.

[9] L. Donati, L. Tomesani, and G. Minak. Characterization of seam weld quality in AA6082 extruded profiles. Journal of Materials Processing Technology, 191:127-131, 2007.

[10] H.H. Jo, S.K. Lee, S.B. Lee, and B.M. Kim. Prediction of welding pressure in the non-steady state porthole die extrusion of Al7003 tubes. International Journal of Machine Tools and Manufacture, 22:753-759, 2002.

[11] L. Filice, F. Gagliardi, and F. Micari. A laboratory scale equipment to relieve force and pressure in cold extrusion of lead hollow components. Key Engineer. Mater., 367:137-144, 2008. 